\title{
The Marivan Plain Archaeological Project: western Iran and its neighbours in the Chalcolithic period
}

\author{
Morteza Zamani Dadaneh ${ }^{1}$, Sirvan Mohammadi Ghasrian ${ }^{2}$, \\ Carlo Colantoni ${ }^{3} \&$ Tim Boaz Bruun Skuldbøl ${ }^{4, *}$
}

The Marivan region of western Iran is not well understood, hence the Marivan Plain Archaeological Project aims to gain new insights into the region's occupation history and cultural interaction with Mesopotamia.

Keywords: Iran, Marivan, Mesopotamia, Chalcolithic, material culture exchange

\section{Introduction}

The Marivan Plain Archaeological Project (MPAP) investigates ancient settlement in one of the westernmost regions of Iran (35.5186N, 46.1756E). Nestled in the Zagros Mountains, the Marivan Plain lies in the province of Kurdistan and is located between two archaeologically important regions of western Iran: the Central Zagros to the south-east, and the Lake Urmia region to the north-east (Figure 1). Previous archaeological studies have mainly focused on these two regions, with little survey conducted on the Marivan Plain.

Directed by Morteza Zamani Dadaneh with the assistance of Sirvan Mohammadi Ghasrian, the MPAP began in 2018 with a survey covering $200 \mathrm{~km}^{2}$ of a valley plain lying in mountainous landscape. The project's aim is to deepen the understanding of settlement and cultural contact in the under-investigated region of the Central Zagros of western Iran. New data from the MPAP has provided insights into not only the development of indigenous settlement and urbanism in the region, but also the extent of cross-cultural exchange between the societies of Mesopotamia and central Iran lying either side of the Zagros mountain range.

The project focuses on the Chalcolithic period and has recorded significant new evidence for settlement trends and material culture interaction in the Marivan region for this period. Of particular interest is the Late Chalcolithic period (4500-3100 BC) and cultural contact with Mesopotamia. Evidence from recent research in the Zagros foothills of Iraq points to complex patterns of cultural interaction with Iran and Mesopotamia during the Late Chalcolithic period (Skuldbøl \& Colantoni 2018). Data from the Marivan Plain may provide

1 Kurdish Studies Institute, University of Kurdistan, 66177-15175 Pasdaran Street, Sanandaj, Kurdistan, Iran

2 Department of Archaeology, University of Tehran, UT 6619-14155, 13 Poorsina Street, Tehran, Iran

3 School of Archaeology and Ancient History, University of Leicester, University Road, Leicester LE1 7RH, UK

4 Department of Cross-Cultural and Regional Studies, University of Copenhagen, Karen Blixens Plads 8, 2300 Copenhagen S, Denmark

* Author for correspondence (Email: tbbs@hum.ku.dk)

(C) Antiquity Publications Ltd, 2019

ANTIQUITY 93 372, e34 (2019): 1-9

https://doi.org/10.15184/aqy.2019.198 


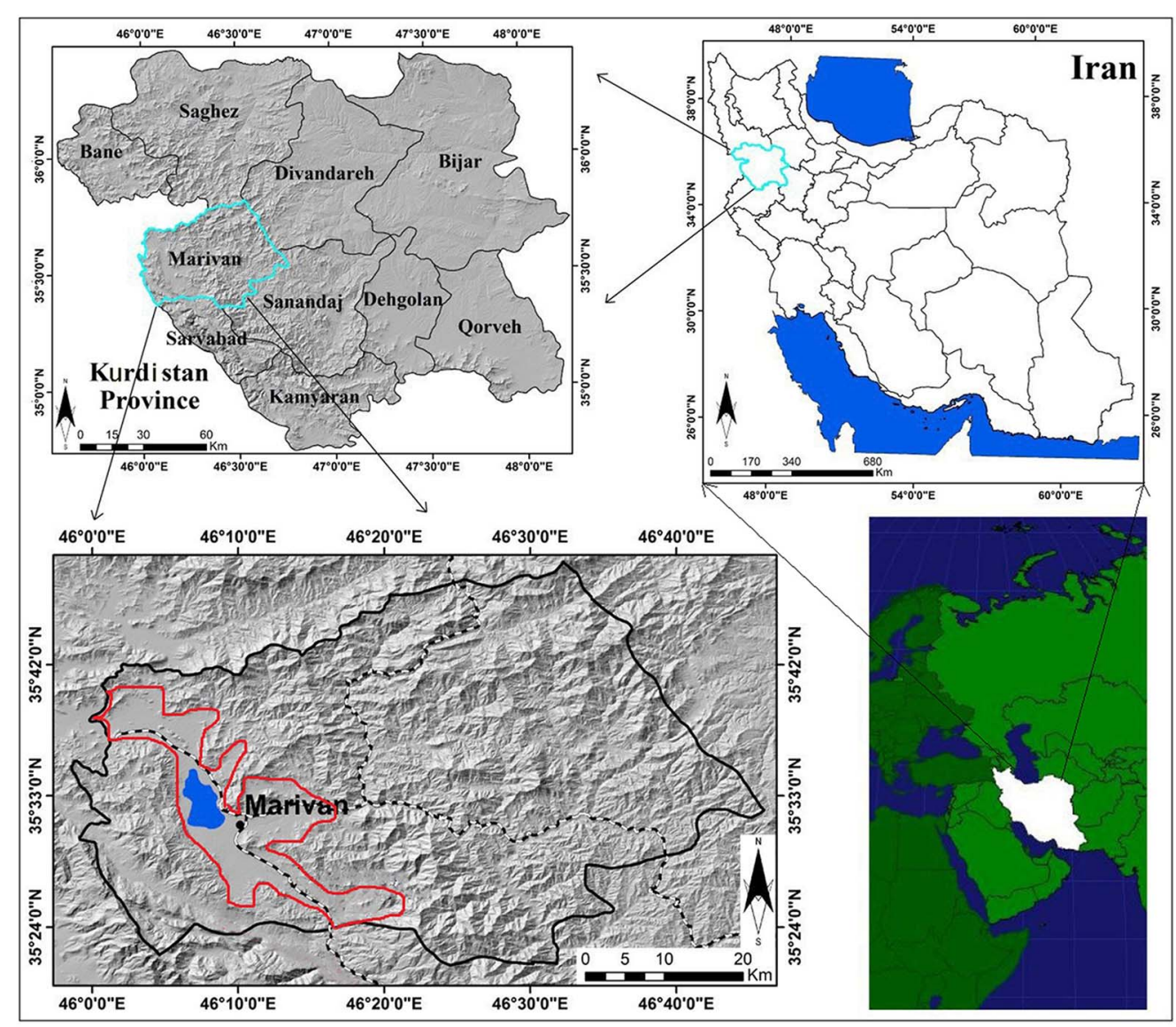

Figure 1. The Marivan Plain, western Iran (@ the Marivan Plain Archaeological Project).

important new insights into cross-cultural expansion and routes of communication into the Iranian highlands during this period, when the plain may have been a cultural transit node between western Iran and Mesopotamia.

\section{8 fieldwork}

Systematic field-walking in the summer of 2018 resulted in the recording of 60 archaeological sites dating from the Neolithic to the Late Islamic periods (Zamani Dadaneh et al. 2019) (Figure 2). Of these, 37 sites were newly discovered by the MPAP; the remaining 23 sites examined by the MPAP have previously been identified by researchers from Bu-Ali Sina University (Hamadan, Iran). Preliminary evidence shows occupation fluctuating over time with peak settlement numbers identified for the Chalcolithic, Iron Age, Parthian and Islamic periods. A range of diagnostic surface finds shows the complexity of archaeological material from the Marivan Plain (Figure 3).

(C) Antiquity Publications Ltd, 2019 


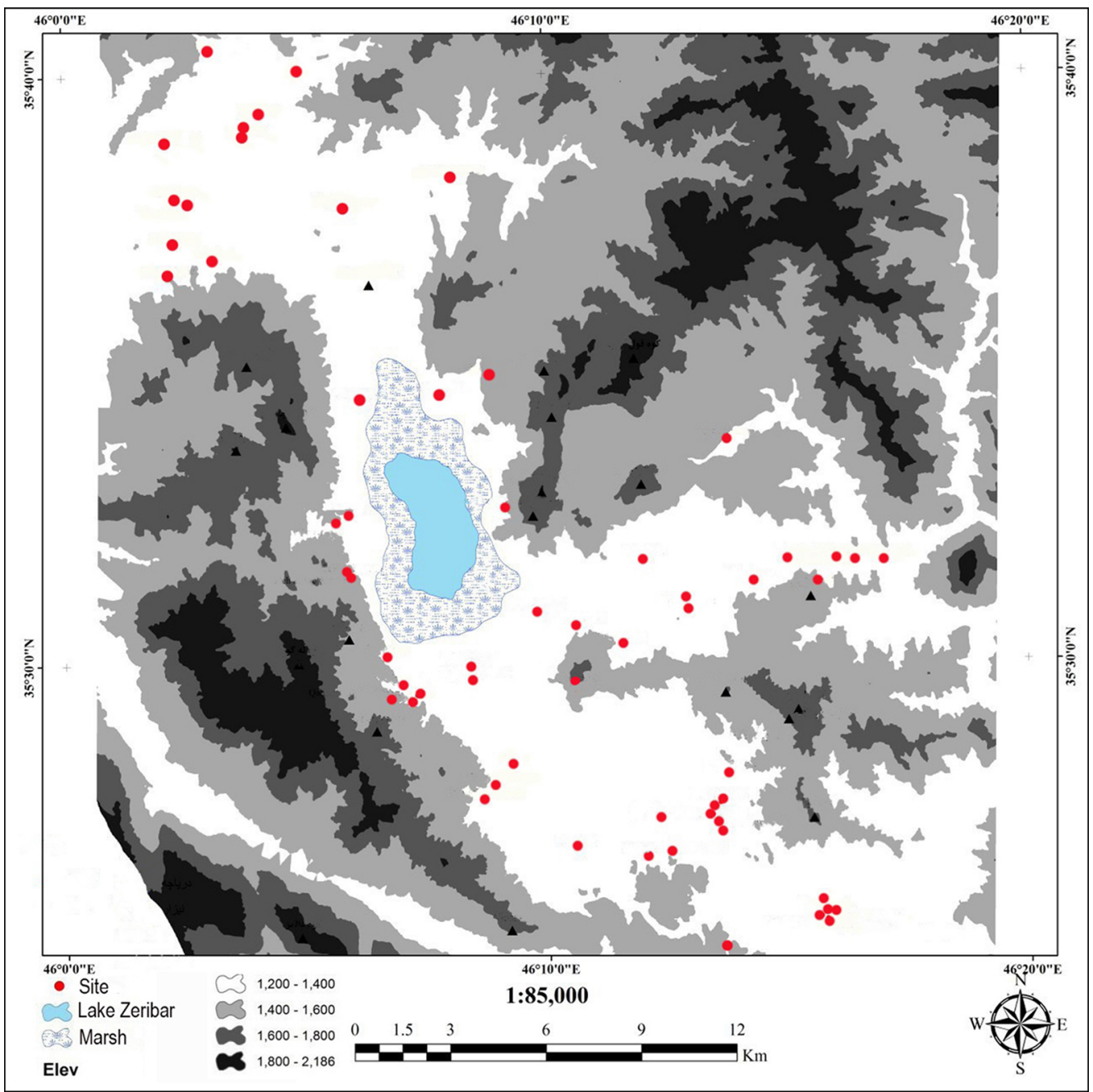

Figure 2. Map of sites registered by the Marivan Plain Archaeological Project (@ the Marivan Plain Archaeological Project).

\section{Insights into the Chalcolithic period}

Cultural interaction in the Marivan region had a varied impact on local groups. The Zagros Mountains may have acted as a physical barrier to direct interaction curtailing or rerouting exchange, possibly via south-western Iran or the Rania plain in Iraq. This is in contrast to earlier periods, where the existence of northern and western Iranian J and Dalma wares and chaff-tempered pottery traditions originating in northern Mesopotamia suggest that external cultural influences permeated the Marivan Plain. As more research is undertaken in the westernmost parts of Iran, the impact of changing cross-regional cultural contact may become clearer.

The MPAP investigations produced important ceramic and material culture evidence of variations in cross-regional interaction for the Chalcolithic period. The earlier Chalcolithic period 


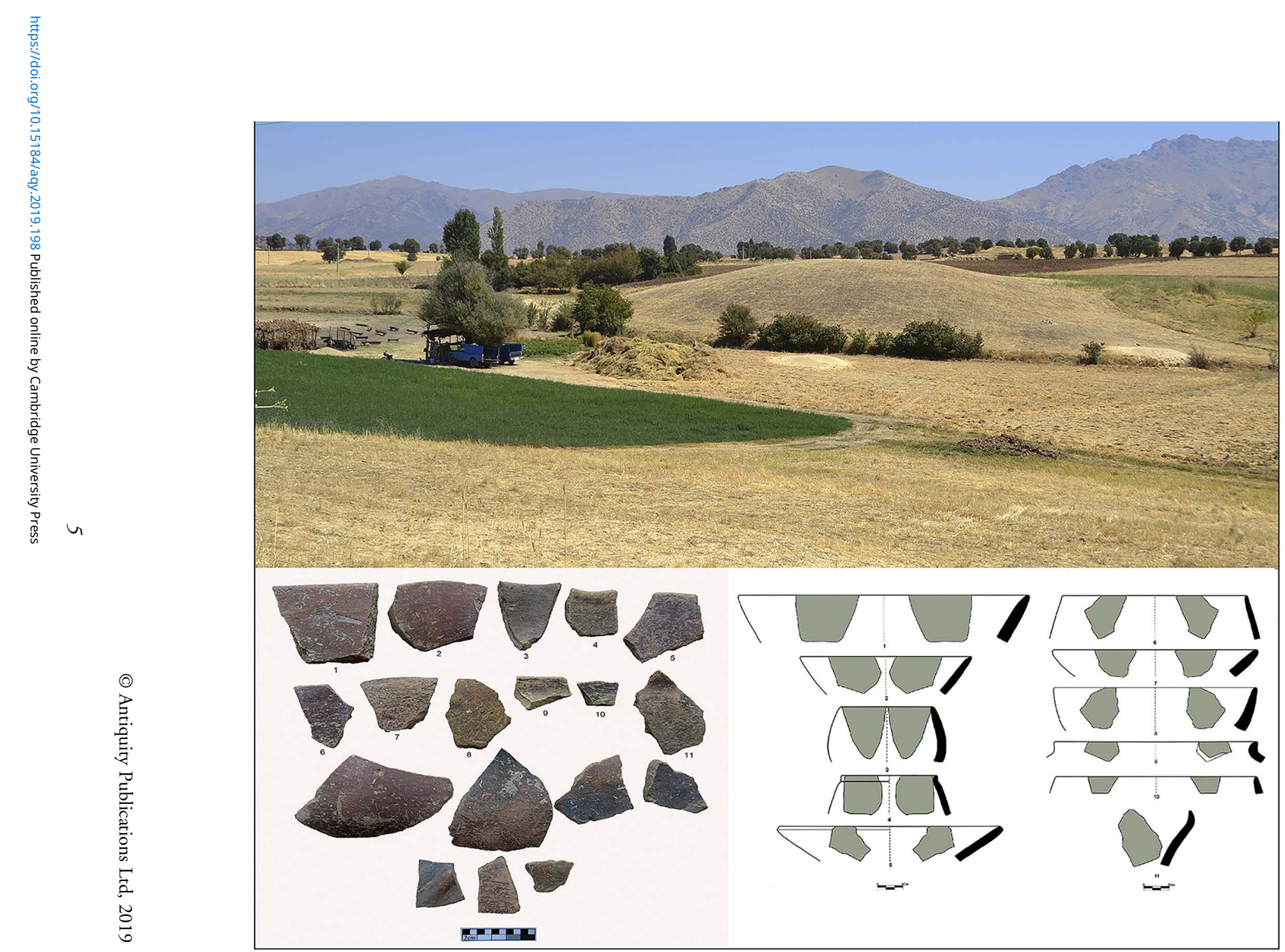

Figure 4. Tepe Qala Zewa and typical J ware-related pottery from the site (@ the Marivan Plain Archaeological Project). 

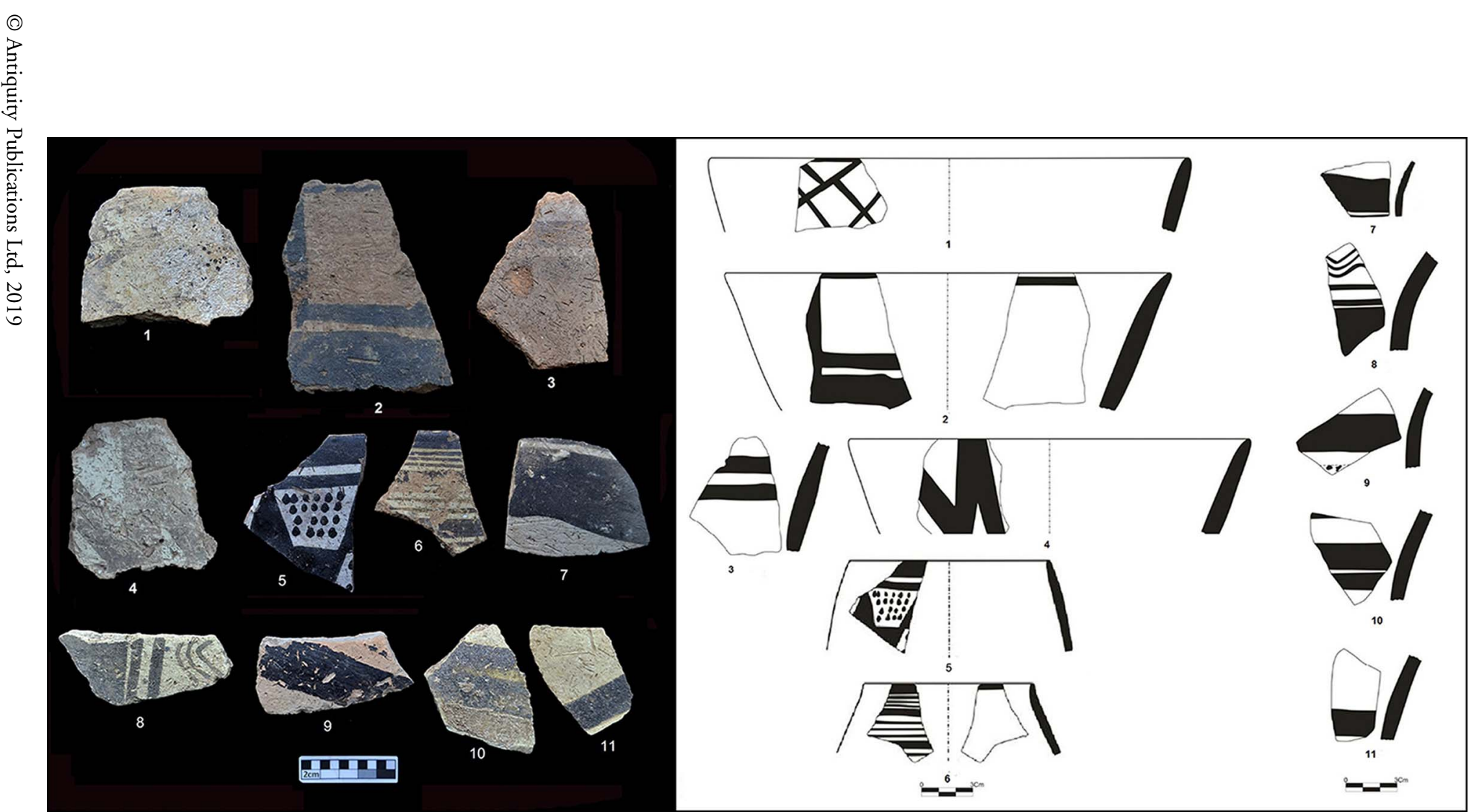

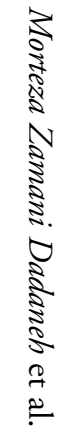

Figure 5. A selection of early Late Chalcolithic pottery from the Marivan Plain (@ the Marivan Plain Archaeological Project). 


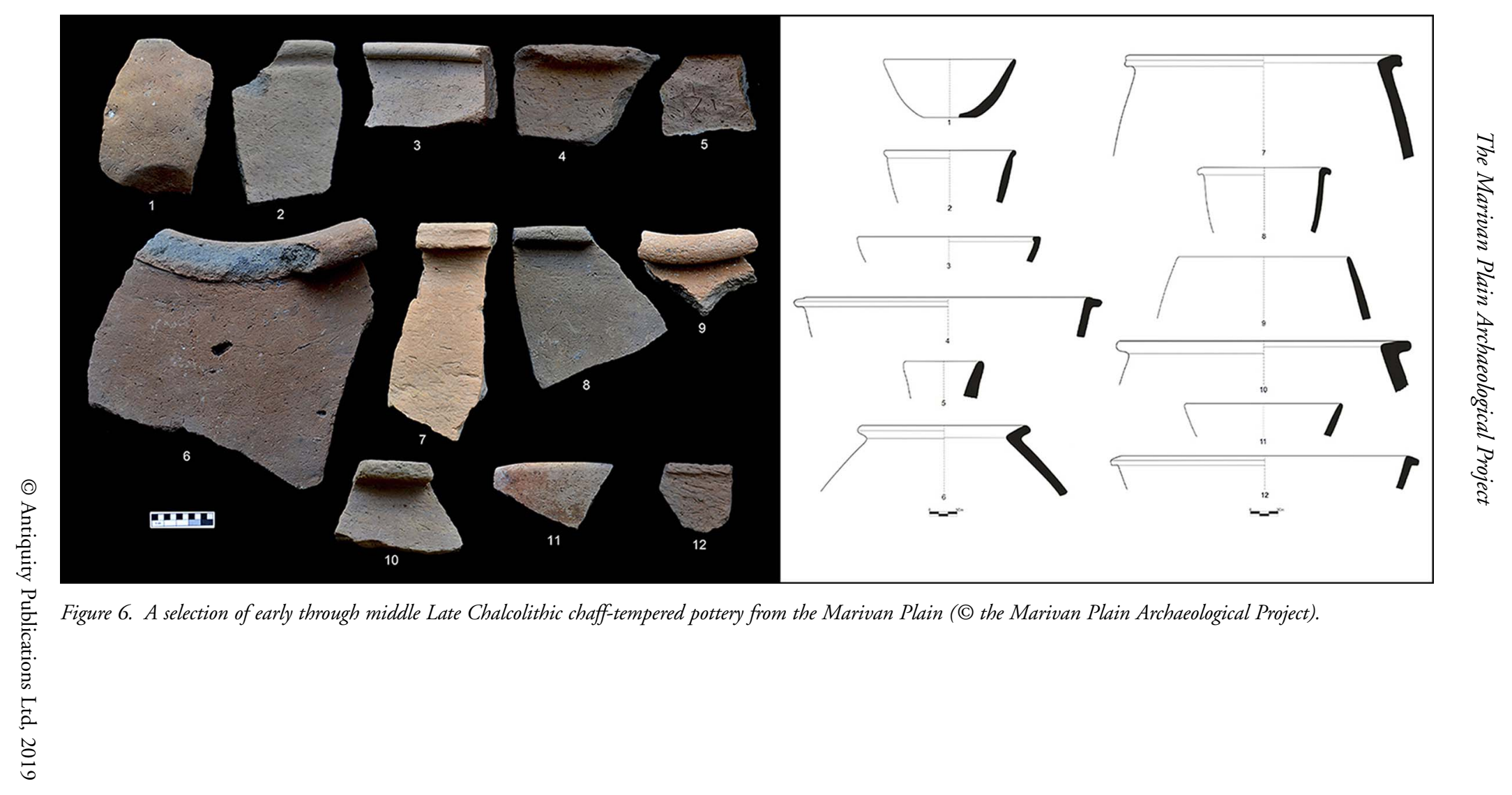

Project Gallery 
is poorly understood in the Marivan region as only one site (Qala Zewa) has so far been identified. Ceramics collected at Qala Zewa are related to the J ware pottery tradition (c. 5500-5000 BC). J ware is considered an Iranian variant of Mesopotamian Late Halaf pottery and has been identified in a number of regions in the Central Zagros (Figure 4) (Levine \& McDonald 1977).

From the Early to Middle Chalcolithic, there is a marginal increase in site numbers, with three small sites identified. All possess highland Dalma and Dalma-related pottery, indicating material cultural links with northern Iran, Central Zagros and north-western Iraq.

For the Late Chalcolithic period, 11 sites have so far been identified. While the earliest Late Chalcolithic (LC1, c. 4500-4200 BC) sites are identified and characterised by painted pottery of local provenance (Figure 5), it is a challenge to understand the early Late Chacolithic period. In the succeeding early to middle Late Chacolithic (LC2-4, 4200-3400 BC), it is possible to identify close parallels to the chaff-tempered pottery traditions of adjacent regions of northern Iraq and Syria (Figure 6). The expansion of coarse chaff-tempered pottery traditions into the Marivan Plain follows a pattern seen in other regions of western Iran and northern Iraq (Helwing 2013).

Throughout the Late Chalcolithic period, contact with southern Mesopotamia is limited. In the Late Chalcolithic (LC4-5 or Godin VI:2-1), only the large site of Tepe Rasha possesses evidence of contact with the south in the shape of the distinctive pottery type related to the Uruk Culture: the Bevelled Rim Bowl (Zamani Dadaneh et al. 2019). This suggests that cultural contact between Uruk Mesopotamia and the local cultures and political entities residing on the Marivan Plain was limited. The new evidence from the Marivan Plain is surprising, as substantial evidence of contact with Uruk Mesopotamia has been found in the central Western Zagros and Central Plateau of Iran (Helwing 2013).

It is now becoming clear that the impact of cultural contact with Uruk Mesopotamia on local communities in the Zagros Mountains of Iran and Iraq varied considerably. Recent surveys in north-western Iran (Binandeh et al. 2012) and in northern parts of the Iraqi foothills of the Zagros Mountains (e.g. Bonacossi \& Iamoni 2015) have identified limited evidence of contact with Uruk Mesopotamia. In contrast, substantial evidence of interaction with Uruk Mesopotamia is found on the Rania, Peshdar, Chemchemal Plains and the Bazian Valley in the Zagros foothills of north-eastern Iraq, as well as on the Sharizor Plain in Iraq-which lies approximately $25 \mathrm{~km}$ west across the mountains from the Marivan Plain (see Skuldbøl \& Colantoni 2018).

\section{Future}

The MPAP will extend fieldwork beyond the valley plain into the surrounding foothills, integrating results into the settlement history of the wider region. This will include an excavation project focusing on the Chalcolithic period and material culture exchange. In addition, the MPAP is developing its collaboration with the Danish Archaeological Expedition to Iran and Iraq (DAEII). The DAEII currently works on the Rania Plain in northern Iraq, and plans are underway to begin a complementary survey and excavation project to the north of the Marivan Plain.

\section{Acknowledgements}

The MPAP was awarded a grant from the Kurdish Studies Institute, University of Kurdistan, and is indebted to Faryad Haddadian, Director of the Marivan cultural heritage office, for his kind assistance.

(C) Antiquity Publications Ltd, 2019 


\section{References}

Binandeh, A., A.H. Nobari, J. Neyestani \& H. Vahdati NaSAB. 2012. New archaeological research in north-western Iran: prehistoric settlements of Little Zab River Basin.

International Journal of Humanities 19(2): 27-41.

Bonacossi, M. \& M. IAmoni. 2015. Landscape and settlement in the eastern Upper Iraqi Tigris and Navkur Plains: the Land of Nineveh Archaeological Project, seasons 2012-2013. Iraq 77: 9-39. https://doi.org/10.1017/irq.2015.5

Helwing, B. 2013. Some thoughts on the mode of culture change in the fourth millennium BC Iranian highlands, in C.A. Petrie (ed.) Ancient Iran and its neighbours: local developments and long-range interactions in the fourth millennium $B C$ : 93-105. Oxford: Oxbow.

https://doi.org/10.2307/j.ctvh1dn46.10

Levine, L.D. \& M.A. McDonald. 1977. The

Neolithic and Chalcolithic periods in the
Mahidasht. Iran XV: 39-50.

https://doi.org/10.2307/4300563

Skuldbøl, T.B.B. \& C. Colantoni. 2018. Culture contact and early urban development in Mesopotamia: is garbage the key to understanding the 'Uruk expansion' in the Zagros foothills of north-eastern Iraq?, in B. Horejs, C. Schwall, V. Müller, M. Luciani, M. Ritter, M. Giudetti, R.B. Salisbury, F. Höflmayer \& T. Bürge (ed.) Proceedings of the $10^{\text {th }}$ International Congress on the Archaeology of the Ancient Near East (volume 2): 639-52. Wiesbaden: Harrassowitz. https://doi.org/10.2307/j.ctvcm4fnh.50

Zamani Dadaneh, M., S. Mohammadi GhasRian \& T.B.B. SкuLdвøL. 2019. Investigating Late Chalcolithic period settlement on the Marivan Plain, western Iran: first insights from the Marivan Plain Survey Project. Ash-Sharq. Bulletin of the Ancient Near East 3: 33-46.

Received: 15 May 2019; Revised: 3 July 2019; Accepted: 12 July 2019 